\title{
Stockpiled limonitic material as a novel source of readily bioleached cobalt
}

\author{
A.D DyBOWSKA ${ }^{1 *}$, P.F. SCHOFIELD ${ }^{1}$, J.F.W. \\ MOSSELMANS $^{2}$ AND R.J. HERRINGTON ${ }^{1}$ \\ ${ }^{1}$ Earth Science, Natural History Museum, London, UK \\ ${ }^{2}$ Diamond Light Source, Harwell Science Campus, UK \\ ( ${ }^{*}$ correspondence: a.dybowska $@$ nhm.ac.uk)
}

Cobalt has unique properties highly valued for many applications essential to the green economy. Its use in rechargeable batteries for electric vehicles, so significant in the transition to a low-carbon economy, is particularly driving the high demand. Cobalt is rarely the primary target of a mine and is usually recovered as a by-product of base metal mining. Indeed, the nickel industry remains the major source of $\mathrm{Co}$ with $\mathrm{Ni}$ laterites supplying $20 \%$ of world's Co.

We have undertaken a mineralogical, chemical and atomistic-scale characterization of limonites from locations including Greece, New Caledonia, Brazil, Kazakhstan, Turkey, Philippines and Cameroon. Combining bulk and spatially resolved techniques, including synchrotron micro-analysis, we imaged the Co distribution, identified the Co-hosting phases and modelled its atomic scale residence. The main determinant of Co enrichment is its preferential association with $\mathrm{Mn}$ oxides, mineralogically identified using EMPA, $\mu$ Raman, FTIR and $\mu$ XRD. Most common were asbolane, lithiophorite and asbolanelithiophorite intermediates. Co varies between 1 and $20 \mathrm{wt} \%$, and is structurally incorporated in these minerals. The predominant $\mathrm{Co}-\mathrm{Mn}$ association in limonites facilitates selective leaching of $\mathrm{Co}$ by microbially-mediated reductive dissolution. 